\title{
Design and Development of Brahmi Extract Loaded Nanofibers for Cognitive Disorder and Its Optimization
}

\author{
Shete Sanmati D.*, Amane Nikita B., Desai Punam S., Dr. Salunkhe .V. R., Dr. Magdum C. S \\ Rajarambapu College of Pharmacy, Kasegaon, Dist - Sangli, Maharashtra, India \\ Corresponding Author E-mail: sanmatidshete123@gmail.com
}

\section{ABSTRACT}

Cognitive disorders (CDs), also known as neurocognitive disorders (NCDs) are a category of mental health disorders that primarily affect cognitive abilities including learning, memory, perception, and problem solving. Global population with depression ranges mostly between $2 \%$ and $6 \%$ around the world today. Mental health disorders are also attributed to significant number of indirect deaths through suicide and self-harm. The aim of designing a drug delivery system is to enable drug release at a controlled rate over a desired period. nanofibers, with their large specific surface areas, can improve the solubility and dissolution rates of drugs, thereby resulting in fast release of poorly soluble active drugs. Drug release from nanofibers in terms of processing setup and modulate the release kinetics, to achieve site of action with increased plasma half life and resulting increasing residence time of drug in plasma, slowing down rapid renal clearance and helping extended presence of drug at the site of action and also minimize the toxicity of drug. Bacopa monniera an Ayurvedic drug which is mainly used for health practices. Polyvinylpyrrolidone as synthetic polymer was preferably used as a carrier for preparation of nanofibers. Nanofibers mainly prepared by using synthetic polymer because it does not have any toxic effect. Pre-formulation studies were carried out. Experimental design based on trial and error base. Total three batches were prepared using chitosan, cellulose acetate and Polyvinylpyrrolidone.FT-IR Spectroscopy study showed that there was no interaction between drug and polymer. Nanofibers were prepared by using electrospinning method. After preparation of nanofibers were subjected to various evolution parameters includes practical yield, in-vitro drug release, drug entrapment efficiency, SEM,XRD, Zeta Potential, FTIR. The formulations were optimized with respect to In-Vitro drug release and drug entrapment efficiency. Among the all formulations, the Brahmi Extract loaded PVP nanofibers batch F1 containing 300mg of brahmi extract and $600 \mathrm{mg}$ polymer was optimized because this batch showed $97.57 \%$ drug release,99.24\% drug entrapment efficiency,-26.4mV Zeta potential of the optimized batch which is mainly used to check the stability of the nanofibers formulation. An optimized formulation brahmi extract loaded nanofibers batch $\mathrm{F} 1$ is well acceptable, pleasant, palatable and with better compliance.

Keywords : Cognitive disorders, brahmi extract loaded PVP nanofibers, Scanning electron microscopy, Zeta potential, In-Vitro drug release, drug entrapment efficiency practical yield, XRD, FTIR.

\section{INTRODUCTION}

Cognitive improvement typically acts as a toxicological and psychological tool. ${ }^{20-23}$ The medium of nootropic phytochemicals discovered in Bacopa monnieri (BM), mainly triperpenoid saponins called bacosides, exhibit minimal observable shows minimal observable negative impacts at ordinar y doses. BM shows anti-oxidant, ${ }^{24}$ hepatoprotective, ${ }^{25}$ and neuroprotective ${ }^{26}$ activity. Emerging analysis 
shows lots of mechanisms of action of brahmi extract -acetylcholinesterase inhibition, choline acetyltransferase activation, $\beta$-amyloid reduction, increased cerebral blood flow and monoamine potentiation.Bacopa monnieri (also known as brahmi, water hyssop, Bacopa monniera, and Herpestis monniera), is a creeping perennial with small oblong leaves and purple flowers, found in warm wetlands, and native to Australia and India. Commonly found as a weed in rice fields, BM grows throughout East Asia and the United States. ${ }^{27}$

Phytochemical based antioxidants may have neuroprotective (preventing apoptosis) and neuroregenerative roles, ${ }^{28}$ by decreasing or reversing cellular damage and by slowing of neuronal cell loss development. In nature, AOX are categorized as endogenous or exogenous. The endogenous group comprises of enzymes such as superoxidase demotes (Zinc, manganese, and copper), glutathione peroxide (selenium) and catalus and albumin, transferin, ceruloplasmin, metallothyinin and haptoglobin. AOX offer a promising strategy to control or slowing down progressive of neurodegenerative disorders such as Alzheimer's disease, parkinson's disease, huntington's disease, amyotrophic lateral sclerosis, ischaemic and haemorrhagic stroke. ${ }^{29,30}$

Several methods, such as the formation of nanoparticles, micelles and liposomes, have been recorded to improve curcumin bioavailability. Although these novel techniques are very promising, some constraints to their apps are still being practiced. The preparation technology and circumstances of curcumin nanoparticles are relatively complicated, so these particles are not appropriate for comprehensive manufacturing. Besides this, the biocompatibility of some of the polymers used in micelles and liposomes is still unknown and therefore this formulation cannot be implemented in clinical therapy. Furthermore, the structural stability and loading capacities of these formulations are also regarded as limitations for their use in practice. ${ }^{33}$

Electrospinning is a versatile and compatible technique to use a large prospective electrical field to create ongoing nanofibers from submicron diameters down to nanometer diameters. Nanofibers with diameters varying from 1-100 nanometers can be produced. ${ }^{34,35}$ These methods can be readily used in the laboratory and can be cultivated in industrial processes ${ }^{36}$. The asspun fibers are mostly gathered in the form of nonwoven nanofiber mat on electrode collectors. It is also feasible to achieve aligned nanofibers using supervised fiber deposition techniques ${ }^{37}$. Optimal nanofibers can be formed by regulating solution, process and ambient parameters, as these parameters determine the features of electrospun fibers. ${ }^{38}$ The engineering of nanofibers is an significant component of nanotechnology. For the first time more than four decades before electrodynamics were created nanofibers. Nanofibers were developed more than four decades before electrodynamics. Nanofibers have nanometer fibers in the range of diameters. ${ }^{39}$ Nanofibers can be produced with distinct polymers and therefore nanofibers have distinct physical characteristics and application strengths. Over the past two decades, ultrafine structures including microspheres and nanostructures such as nanoparticles and nanospheres have been of interest in pharmaceutical science for the formulation of new drug delivery systems, Because of their controllable elevated surface area, surface-to-volume ratio, high porosity and elevated drug loading and controlled payload capacities. ${ }^{40,41}$ Natural polymers include collagen, cellulose, silk, fibroin, keratin, gelatin, and polysaccharides such as chitosan and alginate. ${ }^{42}$ Electrospinning is the most helpful method and can generate ultrafine diameter nanofibers and well-ordered surface morphologies. ${ }^{43}$ 


\section{Advantages of nanofibers ${ }^{46}$}

1. High surface area to volume ratio

2. Ease of fiber functionalization

3. Ease of material combination

4. Relatively low start up cost

5. Low learning curve for basic electrospinning

6. Ease of fiber deposition onto other substrates

7. Variety of nanofibrous structures have been constructed

8. Mass production capability demonstrated

9. Commercial applications:
a) Air filtration membrane
b) Face mask
c) Water filtration membrane
d) Tissue engineering
e) Drug delivery
f) Clothing
g) Wound dressing
h) Battery

\section{OBJECTIVES}

In this study, our goal was to prepare Brahmi Extract loaded nanofibers by electrospinning using polyvinylpyrrolidone (PVP). Furthermore, evaluation of various important factors, such as the applied voltage, feed rate, and the concentrations of the polymer and the drug, was used to determine the effects of these parameters on the different properties of the resulting nanofibers. In addition, in terms of drug-release characterization, the nanofibers are compared to the solid dispersion preparation obtained from the freeze-drying technique.

\section{METHODS AND MATERIAL}

\section{Preparation of Electrospinning Solution}

To prepare the initial solution, 30 and $35 \mathrm{~g}$ of PVP were dissolved in $100 \mathrm{~mL}$ of ethanol. The polymeric solutions were placed on a magnetic stirrer for 15 minutes at room temperature; subsequently, loratadine was added to this solution at ratios of 1: 2 and 1: 4 relative to the weight of the polymer and mixed until the loratadine was completely dissolved.

\section{- Method for Preparation of Brahmi extract loaded PVP nanofibers}

The Brahmi extract loaded nanofibers were prepared by electrospinning technique in ethanol. The PVP polymer was selected for the preparation of Nanofibers. Brahmi extract loaded chitosan nanofibers and cellulose acetate nanofibers were prepared. These batches were failed because there was no formation of nanofibers. The Brahmi extract loaded polyvinylpyrrolidone nanofibers was formed. PVP nanofibers Solution containing $300 \mathrm{mg}$ concentration of Brahmi extract with $600 \mathrm{mg}$ Polyvinylpyrrolidone(Batch $\quad$ F1), $\quad 300 \quad \mathrm{mg}$ concentration of Brahmi extract with $800 \mathrm{mg}$ Polyvinylpyrrolidone(Batch F2) and 300mg concentration of Brahmi extract with $500 \mathrm{mg}$ Polyvinylpyrrolidone(Batch F3) such as (1:2, 1:4 etc) were added 99\%ethanol into PVP-Brahmi extract sample stir by using magnetic stirrer at $50^{\circ} \mathrm{C}$ for 90 min. Then these solutions were placed in ultrasonic bath for $20 \mathrm{~min}$. After that solution added to $20 \mathrm{ml}$ plastic syringe of $10 \mathrm{~mm}$ diameter and syringe was placed in syringe pump and the was connected with high voltage supply. The flow rate were $0.8 \mathrm{ml} / \mathrm{hr}$, tip to collector distance $150 \mathrm{~mm}$, applied voltage $9 \mathrm{KV}$ and needle diameter $0.7 \mathrm{~mm}$. After electrospinning process, the nanofibers were removed from aluminum foil and store in Desicator for further study.

\section{- Formulation of Brahmi extracts loaded nanofibers based on trial and error base}


Table 1.1 : Formulation table of Brahmi extract loaded nanofibers

\begin{tabular}{|c|c|c|c|c|c|c|c|c|c|c|}
\hline $\begin{array}{l}\text { Sr } \\
\text { No }\end{array}$ & $\begin{array}{l}\text { Batch } \\
\text { code }\end{array}$ & $\begin{array}{l}\text { Drug } \\
\text { Conc. } \\
\text { (mg) }\end{array}$ & $\begin{array}{l}\text { Polymer } \\
\text { concentratio } \\
\text { n } \\
\quad(\mathbf{m g})\end{array}$ & $\begin{array}{l}\text { Solvent } \\
\text { Used } \\
(\mathrm{mL})\end{array}$ & $\begin{array}{l}\text { Flow } \\
\text { rate } \\
(\mathbf{m L})\end{array}$ & $\begin{array}{l}\text { Needle } \\
\text { Diamete } \\
\mathbf{r} \\
\quad(\mathbf{n m})\end{array}$ & $\begin{array}{c}\text { Voltage } \\
(\mathrm{Kv})\end{array}$ & $\begin{array}{l}\text { Dru } \\
\text { m } \\
\text { spee } \\
\text { d } \\
\text { (rpm } \\
\text { ) }\end{array}$ & $\begin{array}{l}\text { Distance } \\
\text { bet }^{\mathrm{n}} \\
\text { tip and } \\
\text { collector } \\
(\mathrm{mm})\end{array}$ & Result \\
\hline \multicolumn{11}{|c|}{ A. By Using Polyvinylpyrrolidone(PVP) } \\
\hline 1 & $\mathrm{~F} 1$ & 300 & 600 & \multirow{3}{*}{$\begin{array}{l}\text { Ethanol } \\
+\quad \text { Dis. } \\
\text { Water }\end{array}$} & 1.5 & 10 & 9 & 500 & 150 & \multirow[t]{3}{*}{ formed } \\
\hline 2 & $\mathrm{~F} 2$ & 300 & 800 & & 0.9 & 10 & 10 & 500 & 140 & \\
\hline 3 & F3 & 300 & 500 & & 2 & 10 & 12 & 500 & 150 & \\
\hline
\end{tabular}

\section{- Characterization of Brahmi extract loaded nanofibers}

\section{Practical Yield}

The \% practical yield of all prepared Brahmi extract loaded nanofibers were calculated. For determination of $\%$ practical yield following formula was used

(\%) Yield $=($ Practical yield $) \times 100$

\section{(Theoretical yield)}

\section{Drug Entrapment efficiency ${ }^{78}$}

The entrapment efficiencies of prepared systems were determined by measuring the concentration of free drug was determined by adding $10 \mathrm{mg}$ of nanofibers to $9.9 \mathrm{ml}$ ethanol (95\%) in order to dissolve the unentrapped drug; the obtained suspension was centrifuged for $45 \mathrm{~min}$ at $2000 \mathrm{rpm}$. The Supernatant was separated and then filtered through filter paper $(0.2 \mu \mathrm{m})$. The filtrate was diluted using ethanol and measured spectrophotometrically at $286 \mathrm{~nm}$. The entrapment efficiency was calculated using the following equation.

\section{Entrapment efficiency (\%)}

$$
\text { = Weight of total drug - weight of free drug X } 100
$$

\section{Weight of total drug}

\section{In-vitro drug release study 77}

The drug release of the $10 \mathrm{mg}$ of Brahmi extract loaded PVP nanofibers were measured in order to determine the release profile of the drugs. Samples of Brahmi extract loaded nanofibers sheet were immersed in phosphate buffered saline solution ph 7.4 containing $0.5 \%$ sodium dodecyl sulphate at $37^{\circ} \mathrm{C}$ and samples of PVP-Brahmi extract were immersed in PBS only at $37^{\circ} \mathrm{C}$. This release study was based on the continuous stirring method. The solutions were agitated using a shaker at a rate of $80 \mathrm{rev} / \mathrm{min}$. the UV absorbance of the drug was measured at Brahmi extract $286 \mathrm{~nm}$ respectively. Measurements were taken at intervals at $4 \mathrm{~min}, 8 \mathrm{~min}, 12 \mathrm{~min}, 16 \mathrm{~min}$, $20 \mathrm{~min}$, 24min, $28 \mathrm{~min}, 32 \mathrm{~min}, 36 \mathrm{~min}$ and $40 \mathrm{~min}$. At each point, $4 \mathrm{ml}$ of solution was taken from the vial and replaced with fresh in order to satisfy the perfectsink conditions and keeping the volume of the solution constant. By using this procedure an in-vitro drug release of three batches were studied.

\section{UV-Vis spectroscopy}

The UV-Vis spectrum of Brahmi extract and the Brahmi extract drug loaded PVP nanofibers conjugates were measured with a UV-2550 spectrophotometer (Shimadzu, Kyoto, Japan) to provide direct evidence of the attachment of brahmi extract to the PVP. The absorbance at $786 \mathrm{~nm}$ was 
used to determine the concentration of Brahmi extract in Drug loaded PVP nanofibers using a visible spectrophotometer (Shimadzu,Kyoto, Japan).

\section{Zeta potential determination:}

A $10 \mathrm{mg}$ aliquot of Brahmi extract loaded PVP nanofibers diluted in $0.5 \mathrm{ml}$ of ethanol and $9.5 \mathrm{ml}$ of ultra pure water. After the shaking of this solution properly wait until the proper mixing of the solution. Then clear solution was taken from the mixture and by using the zetasizer zeta potential was determined of optimized batch F1. From the optimized batch sample zeta potential of the Brahmi extract drug loaded PVP nanofibers were determined this diluted sample was transferred to a cuvette and the zeta potential was measured in triplicate using a Delsa ${ }^{\mathrm{TM}}$ Nano zetasizer.

\section{FT IR Spectroscopy}

To determine and interpret functional groups in brahmi extract loaded PVP nanofibers. FTIR of procured sample of drug loaded PVP nanofibers was studied by directly taking the drug loaded nanofibers on the ATR disk and proceed for the next step to monitoring data which was shows the peaks on particular wavelengths. After taking of graphs peaks was found and taken the results for it. The analysis of IR peaks was done by JASCO 4600, Japan spectrometer. From the results data were interpreted with the standard values.

\section{Scanning electron microscopy}

SEM test is carried out for the change in morphology of Brahmi extract loaded PVP nanofibers images were performed on a JSM 6360 images clearly illustrated in different figures, show that the nanofibers synthesized in this study display widely different morphologies according to the values and the concentrations of variable parameters. The SEM image taken at $20 \mathrm{kV}$ with the magnification $15 \mathrm{KX}$,
5KX.These samples however display different mutual orientations.

\section{X- Ray diffraction Spectra}

The particle size and nature of the Brahmi extract loaded PVP nanofibers was determined using X-Ray diffraction. $\mathrm{XRD}$ is a rapid analytical technique primarily used for crystalline phase identification and then provide information on unit cell dimensions. Sample was scanned in the angular range of 100 to 600 in instrument. The drug loaded nanofibers was placed into instrument and X-ray passed through sample and then results were noted.

\section{Short term stability study}

The purpose of stability testing is to provide evidence on how the quality of Brahmi extract loaded PVP nanofibers with time under influence of a variety of environmental factors such as temperature and humidity. Optimized batch F1 selected for short term stability study. Stability studies were carried out for the optimized formulation by storing the formulation at temperature $25^{\circ} \mathrm{C} \pm 2{ }^{\circ} \mathrm{C}$ and $65 \% \pm 5 \%$ relative humidity in stability chamber. The samples were withdrawn periodically after 30 days. Entrapment efficiency and in-vitro drug release was estimated for three months to find any change in the entrapment efficiency drug release kinetics of the prepared Brahmi extract loaded PVP nanofibers.

\section{RESULTS AND DISCUSSION OF BRAHMI EXTRACT LOADED PVP NANOFIBERS}

The prepared batches of Brahmi extract loaded nanofibers were characterized by percentage practical yield, particle size, entrapment efficiency and In-vitro drug release study. From the obtained results, specific batch was selected as optimized batch.

\section{Percentage practical yield}

The results of percent practical yield studies are shown in Table 9.8. The Nanofibers are prepared by 
solvent electrospinning method. From the different ratio of drug, and Polyvinylpyrrolidone, ratio 1:2 shows maximum practical yield. It was found that electrospinning method gives the practical yield in the range of $62-35 \%$. The maximum yield was found $61.70 \%$ in Brahmi extract loaded PVP nanofibers batch F1.

Table.1.2 : Practical yield of Brahmi extract loaded PVP nanofibers

\begin{tabular}{|c|c|c|}
\hline Sr. no & Batch code & \% Yield \\
\hline $\mathbf{1}$ & F1 & $61.70 \%$ \\
\hline $\mathbf{2}$ & F2 & $38.11 \%$ \\
\hline $\mathbf{3}$ & F3 & $34.95 \%$ \\
\hline
\end{tabular}

\section{Determination of entrapment efficiency of Brahmi extract loaded PVP nanofibers}

The entrapment efficiency of prepared nanofibers was carried out by ultra centrifugation method. The drug: PVP (Polyvinylpyrrolidone) ratio 1:2 found to be maximum drug entrapped. The batch F1 shows maximum drug content capacity. The drug entrapment efficiency was found to be $91.60 \%$. This result is summarized in Table no 9.9.

Table 1.3 : \% Entrapment efficiency of Brahmi extract loaded PVP nanofibers

\begin{tabular}{|c|c|c|}
\hline Sr.No & Batch Code & $\begin{array}{c}\text { \%Drug Entrapment } \\
\text { Efficiency }\end{array}$ \\
\hline 1 & F1 & 99.44 \\
\hline 2 & F2 & 98.03 \\
\hline 3 & F3 & 97.76 \\
\hline
\end{tabular}

\section{In-Vitro drug release study of Brahmi extract} loaded PVP nanofibers

Table no 9.13 shows the comparison between drug release rates of all the batches. From the observation it is clearly seen that the drug release rate of batch F1 is highest by graphical representation in comparison with remaining 2 batches F2 and F3.

Table 1.4\% Drug release of Brahmi extract drug loaded PVP nanofibers of all the batches

\begin{tabular}{|l|l|l|l|l|}
\hline $\begin{array}{l}\text { Sr. } \\
\text { No }\end{array}$ & $\begin{array}{l}\text { Time } \\
(\mathbf{m i n})\end{array}$ & F1 (\%) & F2 (\%) & F3 (\%) \\
\hline 1 & 0 & 0 & 0 & 0 \\
\hline 2 & 4 & 24.50 & 16.27 & 18.12 \\
\hline 3 & 8 & 30.89 & 20.38 & 22.03 \\
\hline 4 & 12 & 47.95 & 46.75 & 31.75 \\
\hline 5 & 16 & 54.78 & 46.95 & 33.77 \\
\hline 6 & 20 & 57.25 & 54.37 & 38.10 \\
\hline 7 & 24 & 62.19 & 55.60 & 41.60 \\
\hline 8 & 28 & 67.55 & 60.34 & 45.51 \\
\hline 9 & 32 & 70.02 & 63.63 & 48.81 \\
\hline 10 & 36 & 76.40 & 63.22 & 52.51 \\
\hline 11 & 40 & 97.52 & 63.22 & 52.92 \\
\hline
\end{tabular}

\section{RESULTS AND DISCUSSION}

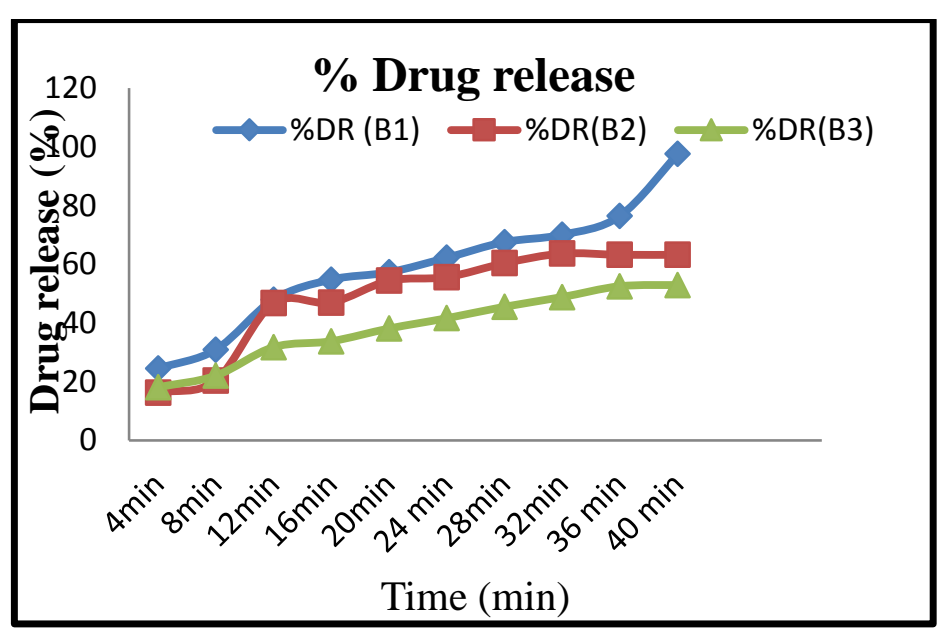

Figure 1.1 : Comparative Graphical Presentation of in-vitro \% drug release for Brahmi extract loaded PVP nanofibers 


\section{FTIR of pure Brahmi extract loaded nanofibers}

The IR spectra of pure drug Brahmi extract loaded PVP nanofibers shows sharp peak at $1741.41 \mathrm{~cm}-1$ which shows presence of $\mathrm{C}=\mathrm{O}$ stretch of ester group. $1650.77 \mathrm{~cm}-1$ shows presence of medium $\mathrm{N}-\mathrm{H}$ primary amine. There is presence of $\mathrm{C}-\mathrm{N}$ stretch of aliphatic amine at $1027.5 \mathrm{~cm}-1$. C-O stretch of alcohol is presented at $1157.08 \mathrm{~cm}-1$. There is sharp peak at $2923.58 \mathrm{~cm}-1$ which shows the alkene (= $\mathrm{CH}$ bend). Figure9.8 shows FTIR spectra of Brahmi Extract in the range of $4000 \mathrm{~cm}-1$ to $400 \mathrm{~cm}-1$ and Table 9.11 shows the data interpretation of Brahmi extract loaded PVP nanofibers.

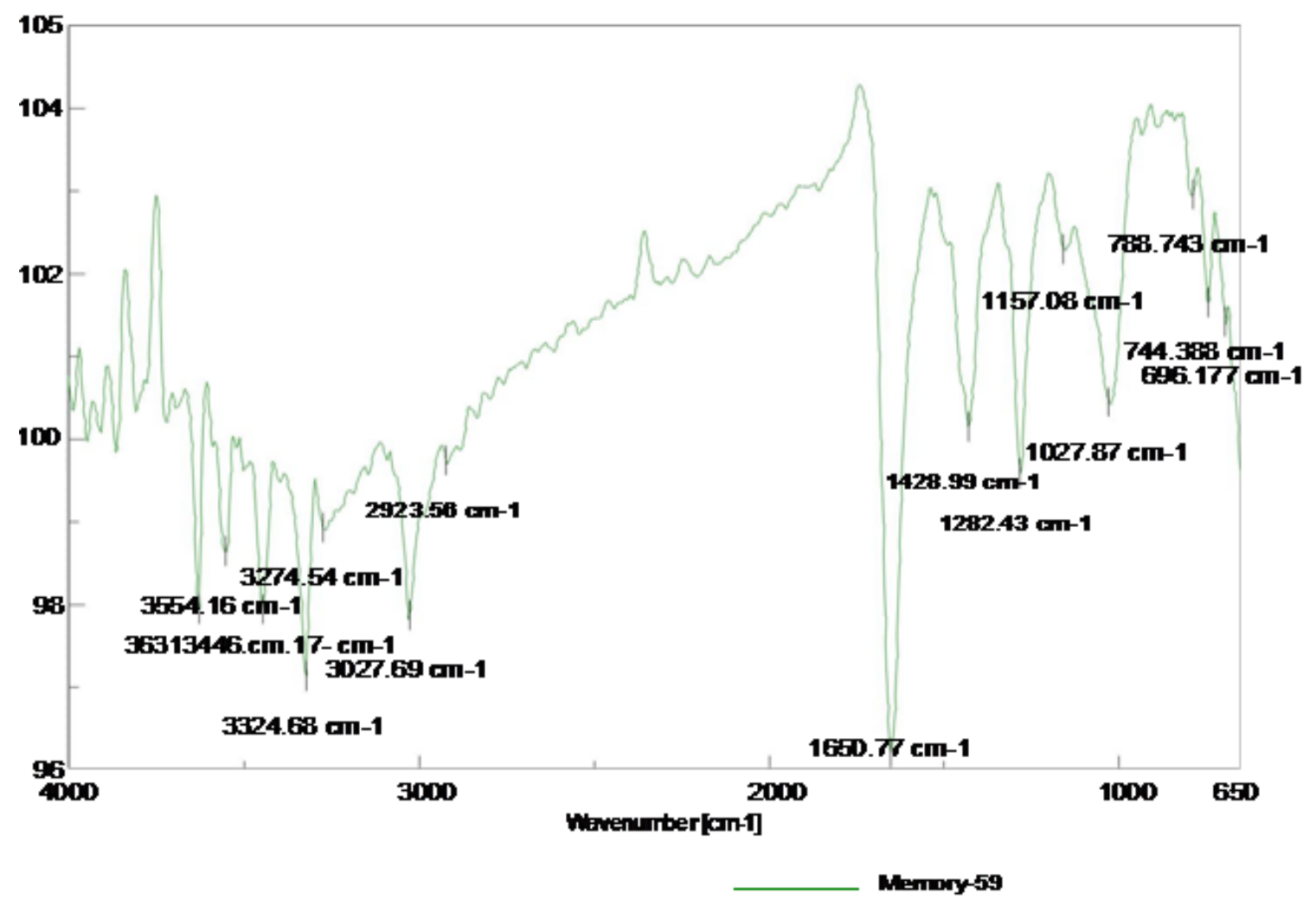

Figure 1.2 : IR Spectra of Brahmi extract loaded Polyvinylpyrrolidone nanofibers

Table 1.5 : IR data interpretation of Brahmi extract loaded PVP nanofibers

\begin{tabular}{|c|c|c|c|}
\hline $\begin{array}{c}\text { Sr. } \\
\text { No }\end{array}$ & $\begin{array}{c}\text { Wave number } \\
\left(\mathbf{c m}^{-1}\right)\end{array}$ & Vibration & Functional Group \\
\hline $\mathbf{1}$ & 696.177 & Bending & C-H monosubstituted \\
\hline $\mathbf{2}$ & 744.388 & Bending & C-H 1,4 disubstituted \\
\hline $\mathbf{3}$ & 788.744 & Stretching & C=C alkene \\
\hline $\mathbf{4}$ & 1027.87 & Stretching & C-N secondary amide \\
\hline $\mathbf{5}$ & 1157.08 & Stretching & C-O primary alcohol \\
\hline $\mathbf{6}$ & 1282.79 & Stretching & C-O primary alcohol \\
\hline
\end{tabular}




\begin{tabular}{|c|c|c|c|}
\hline $\mathbf{7}$ & 1650.77 & Bending & C=O secondary amide \\
\hline $\mathbf{8}$ & 2923.68 & Stretching & C-H alkene \\
\hline $\mathbf{9}$ & 3027.69 & Stretching & O-H alcohol \\
\hline 10 & 3274.54 & Stretching & O-H alcohol \\
\hline 11 & 3446.0 & Stretching & O-H primary alcohol \\
\hline 12 & 3554.16 & Stretching & O-H alcohol \\
\hline 13 & 3631.17 & Stretching & O-H alcohol \\
\hline
\end{tabular}

\section{Zeta Potential}

Optimized nanofibers were analyzed to determine their zeta potential values. The zeta potential value of nanofibers ranging between $25 \mathrm{mV}$ to $-35 \mathrm{mV}$ shows good stability of fibers. It was observed that for optimized formulation of Brahmi extract loaded nanofibers batch F1 zeta potential value was found to be $26.7 \mathrm{mV}$ indicating good stability of the formulation. Figure 9.9 shows zeta potential of optimized batch.
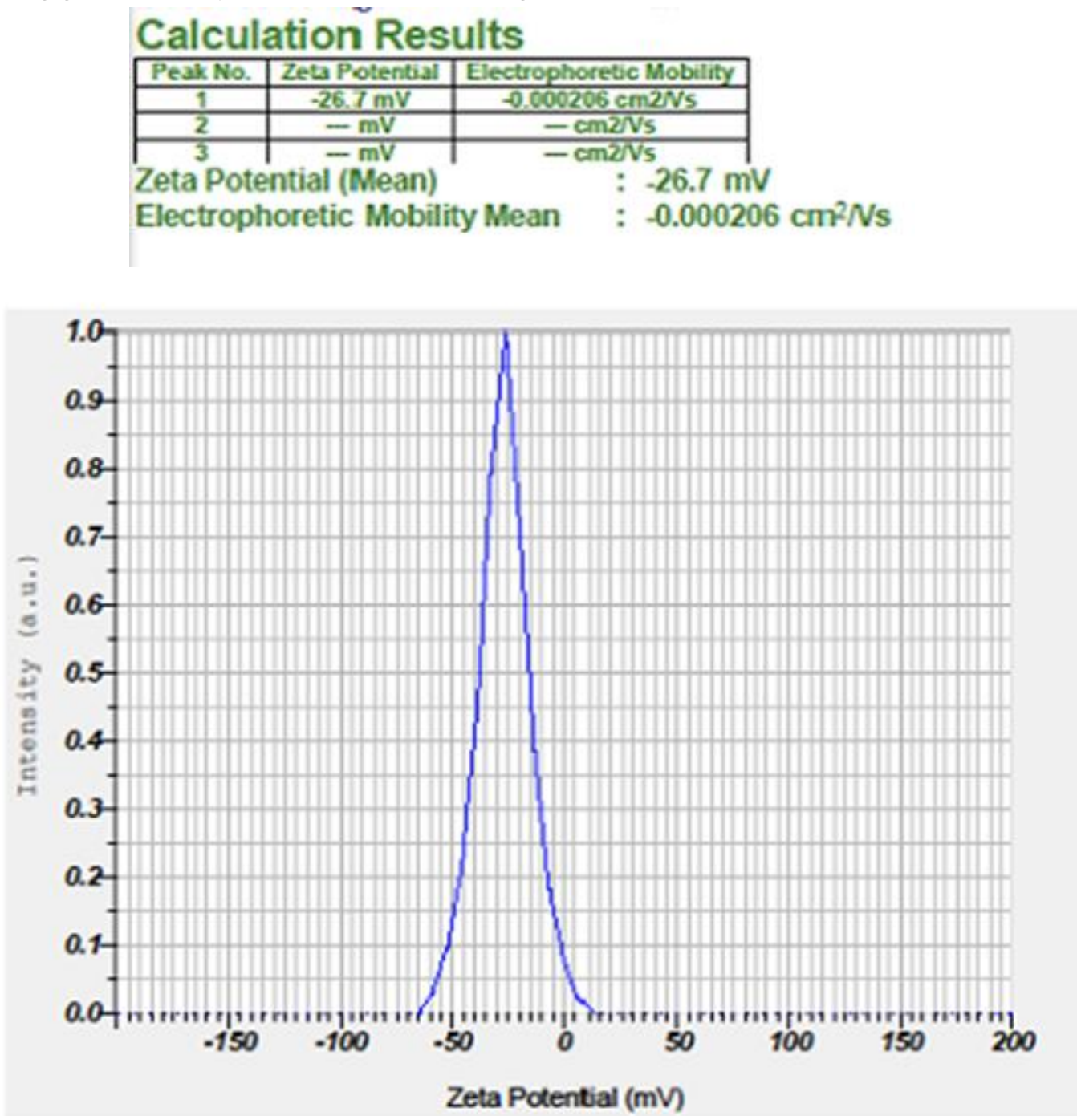

Figure 1.3 : zeta potential of Brahmi extract loaded nanofibers 


\section{UV visible Spectroscopy}

The UV absorbance was taken on Shimadzu UV spectrophotometer and the absorbance of before and after the drug loading reaction was taken as the process going trough drug loading mechanism. The absorbance after drug loading was found to be 0.350 nm.

\section{Scanning Electron Microscopy}

The surface morphology of Brahmi Extract Loaded PVP Nanofibers as shown in Figure 9.12 (a), and 9.13(b) indicates the presence of fiber shape of complex. Result of surface characterization reveals that uniform fiber shape of Brahmi Extract Loaded PVP nanofibers with $450 \mathrm{~nm}$ at $15 \mathrm{KX}$ shows optimum uniform size.

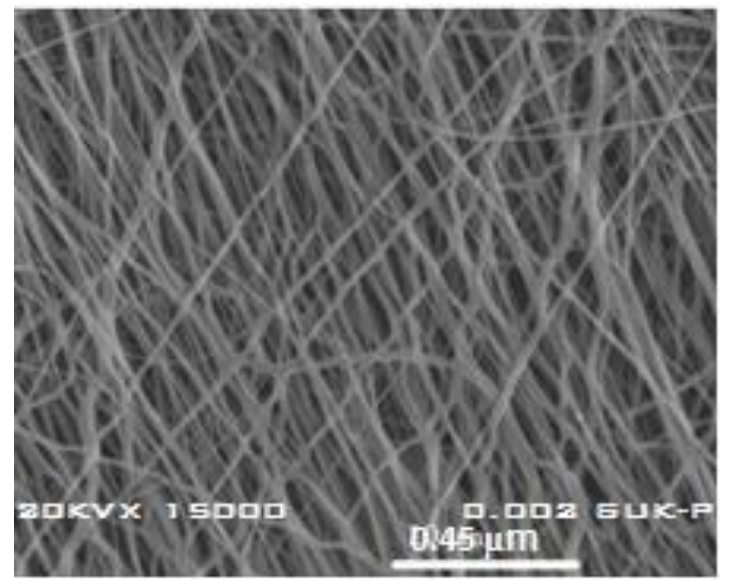

Figure 1.4 a : Morphology of Brahmi extract loaded nanofiber

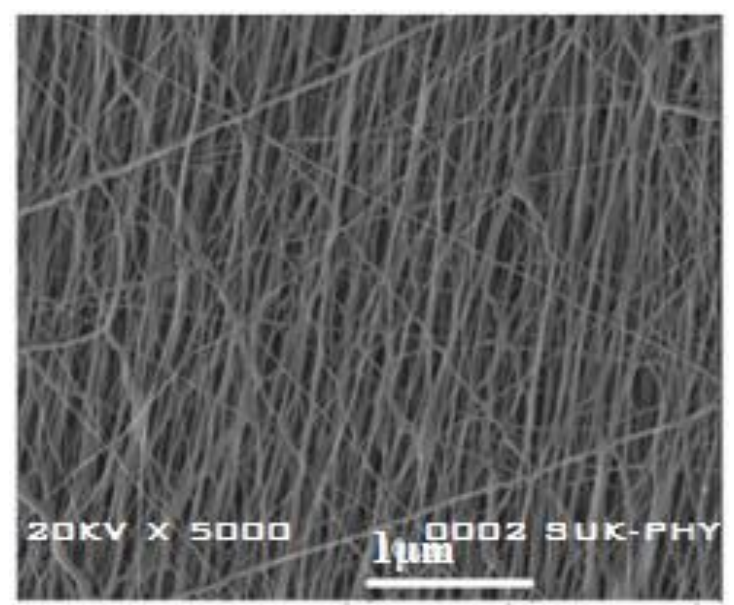

Figure $1.4 \mathrm{~b}$ : Morphology of Brahmi Extract loaded nanofibers

\section{X- Ray diffraction}

Figure 9.10 shows XRD spectra of prepared Nanofibers. Dried sample was analyzed under XRD instrument the result was shown that given sample contains crystalline material in the sample. A sharper peak indicates that more crystalline structure present in the sample.

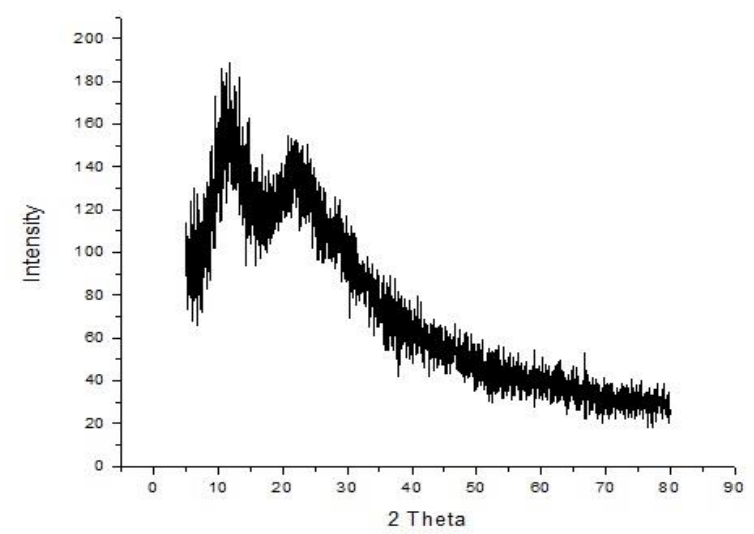

Figure 1.5 : XRD Pattern of Brahmi extract of prepared nanofibers

\section{Short Term Stability studies of optimized formulation}

Stability studies were conducted on Brahmi Extract loaded nanofibers optimized formulation. The sample was withdrawn periodically after 30 days. Stability studies conducted for 90 days. After performing the stability study it was observed that at intermediate stability condition there was no change in the entrapment efficiency as well as drug release from prepared Brahmi extract loaded PVP nanofibers. From this study it is concluded that the prepared Brahmi extract loaded nanofibers formulation were stable during storage. Observed data of stability studies of optimized formulation shown in Table 1.6 
Table 1.6 : Stability study of optimized Brahmi extract loaded PVP nanofibers batch F1

\begin{tabular}{|l|l|l|l|l|l|}
\hline Formulation & Test & $\begin{array}{l}\text { Immediately } \\
\text { after } \\
\text { preparation }\end{array}$ & $\begin{array}{l}\mathbf{3 0 t h} \text { Day } \\
\mathbf{2 5}^{\mathbf{0}} \mathbf{C} \pm \mathbf{2}^{\mathbf{0}} \mathbf{C} / \\
\mathbf{6 5 \%}_{\mathbf{6}} \mathbf{5 \%}\end{array}$ & $\begin{array}{l}\mathbf{6 0 t h D a y} \\
\mathbf{2 5}^{\mathbf{0}} \mathbf{C} \pm \mathbf{2}^{\mathbf{0}} \mathbf{C} / \\
\mathbf{6 5 \%} \mathbf{5 \%}\end{array}$ & $\begin{array}{l}\mathbf{9 0 t h} \text { Day } \\
\mathbf{2 5}^{\mathbf{0}} \mathbf{C} \pm \mathbf{2}^{\mathbf{0}} \mathbf{C} / \\
\mathbf{6 5 \%} \mathbf{5 \%}\end{array}$ \\
\hline Batch 9 & $\begin{array}{l}\text { Entrapment } \\
\text { efficiency }\end{array}$ & $99.44 \%$ & $99.10 \%$ & $99.01 \%$ & $98.95 \%$ \\
\hline $\begin{array}{l}\text { In vitro } \\
\text { drug } \\
\text { release }\end{array}$ & $97.52 \%$ & $97.35 \%$ & $97.13 \%$ & $97.01 \%$ \\
\hline
\end{tabular}

\section{SUMMARY AND CONCLUSION}

Based on preformulation studies for various tests such as organoleptic properties, UV and FTIR spectroscopic study, drugs and excipients were characterized. The study of compatibility with drugs and excipients was conducted. Drugs and excipients were discovered to be consistent with the outcomes to each other. There was not formation of any new compound.

The nanofibers batches F1 to F3 were ready with the use trial and error method. Brahmi extract Electrospinning technique was used to prepare charged nanofibers. In all the lots of formulations F1 to F3, drug concentration was kept constant and polymer concentration was varied. From obtained results of all nanofibers batches it is drug: polymer concentration is required.

The prepared nanofibers batches (F1 to F3) were characterized for different parameters like \% practical yield, entrapment efficiency, and determination of zeta potential, Electron microscopy scanning, X-ray diffraction research and nanofibers Prepared drug release in vitro research. From the various drug ratio: polymer ratio, 1:2 ratio indicates maximum effectiveness of drug trapping and release of drug in vitro.
The entrapment efficiency of Ultracentrifugation technique was used to prepare for the nanofibers. The effectiveness of drug trapping was discovered to be $99.40 \%$ and $97.54 \%$ of drug release in vitro. From this the brahmi extract loaded PVP nanofibers batch F1 batch. The optimized batch F1 further evaluated for determination of, spectroscopic analysis of X-ray diffraction.

For the good stability of prepared nanofibers formulation, Nanofibers ' zeta potential should range from $25 \mathrm{mv}$ to $-35 \mathrm{mv}$. To determine their zeta potential values, optimized nanofibers were evaluated. It has been noted for optimized formulation brahmi extract loaded PVP nanofibers batch F1 has zeta potential value $-26.4 \mathrm{mV}$ An indication of excellent formulation stability. Using scanning electron microscopy, Drug lipid and polymer complex (nanofibers) surface morphology was conducted. The result demonstrates that fiber shape. was found in the in vitro release of drugs research depends upon optimum drug: polymer ratio and particle size of prepared nanofibers.

The formulation Brahmi extracts loaded nanofibers batch $\mathrm{F} 1$ containing the optimum drug: polymer ratio 1: 2, shows the maximum drug release from nanofibers batch F1within $40 \mathrm{~min}$. As we increase the concentration of polymer there was decreases the 
drug entrapment of drug in polymeric nanofibers and also decreases the drug release.

From all results, formulation Brahmi extract loaded PVP nanofibers batch F1 containing 1:2 drug: polymer ratio was optimized formulation having maximum drug release $97.52 \%$ within period of 40 min. with maximum drug entrapment efficiency that is $99.44 \%$ and zeta potential $-26.4 \mathrm{mV}$ showing good stability of formulation. The nature of prepared nanofibers was performed with X-ray diffraction spectroscopy. less diffused peaks in the X-Ray diffraction spectrum indicates that pure drug Brahmi extract material. Sharper peaks of diffraction show more crystallize the drug. An optimized formulation of Brahmi extract loaded PVP nanofibers batch F1 was well acceptable and palatable with better absorption and stability.

\section{REFERENCES}

[1]. A. Mohamed," Modafinil has the potential for addiction" AJOB Neuroscience, 2012;3, P: 3638.

[2]. S. Darke, S. Kaye, R. McKetin, J. Duflou, "Physical and psychological harms of psychostimulant use", National Drug and Alcohol Research Center, 2007, P: 248.

[3]. S. Bell, J. Lucke, W. Hall, "Lessons for enhancement from the history of cocaine and amphetamine use",AJOB Neurosci., 2012; 3,P:24-29.

[4]. DG. Blazer, CF. Federspiel WA. Ray, W. Schaffner, "The risk of anticholinergic toxicity in the elderly: A study of prescribing practices in two populations", J Gerontol.,1983; 38,P:3135.

[5]. YB. Tripathi, S. Chaurasia, E. Tripathi, A. Upadhyay, GP. Dubey, "Bacopa monniera Linn. as an antioxidant: Mechanism of action",Indian J Exp Biol. 1996;34,P:523-526.
[6]. T. Ghosh, TK. Maity, M. Das, A. Bose, DK. Dash, "In vitro antioxidant and hepatoprotective activity of ethanolic extract of Bacopa monnieri", IJPT,2007;6,P:77-85.

[7]. M. Rastogi, R.Ojha, PC. Prabu, DP. Devi, A. Agrawal, GP. Dubey, "Prevention of ageassociated neurodegeneration and promotion of healthy brain ageing in female Wistar rats by long term use of bacosides", Journal of Biogerontology.,2012; 13,P:183-195.

[8]. Barrett SC. Strother JL. Taxonomy and natural history of Bacopa in California. Syst Bot.1978; 5,P:408-419.

[9]. B. Moosmann, C. Behl, "Antioxidants as treatment for neurodegenerative disorders", Expert Opin Investig Drugs, 2002; 11,P:140735.

[10]. M.Berger, M. Can, "oxidative damage is treated nutritionally" Clin Nutr, 2005; 24,P:172-83.

[11]. R.A.Floyd, "Antioxidants, oxidative stress and degenerative neurological disorders" Proc Soc Exp Biol Med. 1999;P:236-45. Dr.Somkant V. Jawarkar, Sanmati D. Shete, Dr. Sandeep R. Kane, "Green Synthesis of silver Nanoparticles using Bacopa Monneeri leat extract and assessment of their DPPH activity" Indo American Journal of Pharmaceutical Research, vol 8, 2019,P:1876-1883.

[12]. Dr.Somkant V. Jawarkar, Sanmati D. Shete, Dr. Sandeep R. Kane, "Green Synthesis of silver Nanoparticles using Bacopa Monneeri leat extract and assessment of their DPPH activity" Indo American Journal of Pharmaceutical Research, vol 8, 2019,P:1876-1883.

[13]. S. Ramakrishna, "A review on electrospinning design and nano-fiber assemblies", Nanotechnology, 2006, 17(14), P:89-106.

[14]. J. Doshi, D H. Reneker, "Electrospinning process and applications of electrospun fibers",Journal of Electrostat, 1995, 35(23)P:151-160. 
[15]. D. H. Reneker, I. Chun, "Nanometer diameter fibres of polymers, produced by electrospinning", Nanotechnology, 1996, 7(3),P: 216-223.

[16]. A. L. Yarin, S. Koombhongse, D. H. Reneker, "Bending instability in electro-spinning of nanofibers", journal of Appl Phys, 2001, 89(5),P:3018-3026.

[17]. $\mathrm{T}$ Subbiah, $\mathrm{G} \mathrm{S}$ Bhat, $\mathrm{R}$ W Tock, "Electrospinning of nanofibers",Journal of Appl Polym Sci, 2005, 96(2),P:557-569.

[18]. V. Hasirci, E. Vrana, P. Zorlutuna "Nanobiomaterials: a review of the existing science and technology and new approaches", Journal of Biomaterial Sci. Polym.Edn, 17 (11), 2006, P: 1241-1268.

[19]. T. Subbiah, G.S. Bhat, RW. Tock, S. Parameswaran, S.S. Ramkumar, " Electrospinning of nanofiber",. Journal of Appl Polym Sci,96, 2005,P:557-569.

[20]. W.E. Teo, S. Ramakrishna, "A review on electro spinning design and nanofibers assemblies" Jounal of Nanotechnology, 17,2006, P:89-106.

[21]. Amandeep Singh, Singh Narinder," Recent Review on Nanofiber for drug delivery system" World Journal of Pharmaceutical Research, April 2017, Volume 6, P:611-631.

[22]. F A A Ruiter, C Alexander, F R A J Rose and J I Segal "A design of experiments approach to identify the influencing parameters that determine poly-D,L-lactic acid (PDLLA) electrospun scaffold morphologies" IOP Publication Ltd Biomedical Materials, Volume 12( 5),P:148-65

[23]. N. Bhardwaj, \& S.C Kundu, "Electrospinning: A fascinating fiber fabrication technique", Biotechnology Advances, 2010, P:325-347.

[24]. Nick Tucker, Jonathan J. Stanger, Mark Staiger ",History of the science and technology of electrospinning",2012,AJRS.

[25]. Electrospintech.com/espinhistory.html.

\section{Cite this article as :}

Shete Sanmati D., Amane Nikita B., Desai Punam S., Dr. Salunkhe .V. R., Dr. Magdum C. S., "Design and Development of Brahmi Extract Loaded Nanofibers for Cognitive Disorder and Its Optimization", International Journal of Scientific Research in Science and Technology (IJSRST), Online ISSN : 2395-602X, Print ISSN : 2395-6011, Volume 6 Issue 6, pp. 104-115, November-December 2019. Available at doi : https://doi.org/10.32628/IJSRST196526 Journal URL : http://ijsrst.com/IJSRST196526 